\title{
Cardiovascular Events Following Smoke-Free Legislations: An Updated Systematic Review and Meta-Analysis
}

\author{
Miranda R. Jones • Joaquin Barnoya • Saverio Stranges • \\ Lia Losonczy • Ana Navas-Acien
}

Published online: 20 June 2014

(C) Springer International Publishing AG 2014

\begin{abstract}
Background Legislations banning smoking in indoor public places and workplaces are being implemented worldwide to protect the population from secondhand smoke exposure. Several studies have reported reductions in hospitalizations for acute coronary events following the enactment of smokefree laws.

Objective We set out to conduct a systematic review and meta-analysis of epidemiologic studies examining how
\end{abstract}

Electronic supplementary material The online version of this article (doi:10.1007/s40572-014-0020-1) contains supplementary material, which is available to authorized users.

\section{R. Jones}

Johns Hopkins University Bloomberg School of Public Health, Baltimore, MD, USA

J. Barnoya

Division of Public Health Sciences, Department of Surgery,

Washington University in St. Louis, St. Louis, MO, USA

\section{S. Stranges}

Division of Health Sciences, University of Warwick Medical School,

Coventry, UK

\section{Losonczy}

Highland Hospital of Alameda County, Oakland, CA, USA

\section{R. Jones $(\bowtie) \cdot A$. Navas-Acien}

Department of Epidemiology, Johns Hopkins Bloomberg School of Public Health, 615 N Wolfe St, Office E6133, Baltimore, MD 21205, USA

e-mail: mijones@jhsph.edu

\section{A. Navas-Acien}

Department of Environmental Health Sciences, John Hopkins University Bloomberg School of Public Health, Baltimore, MD, USA

\section{A. Navas-Acien}

Welch Center for Prevention, Epidemiology, and Clinical Reasearch, John Hopkins University Bloomberg School of Public Health, Baltimore, MD, USA legislations that ban smoking in indoor public places impact the risk of acute coronary events.

Methods We searched MEDLINE, EMBASE, and relevant bibliographies including previous systematic reviews for studies that evaluated changes in acute coronary events, following implementation of smoke-free legislations. Studies were identified through December 2013. We pooled relative risk (RR) estimates for acute coronary events comparing post- vs. prelegislation using inverse-variance weighted random-effects models.

Results Thirty-one studies providing estimates for 47 locations were included. The legislations were implemented between 1991 and 2010. Following the enactment of smoke-free legislations, there was a $12 \%$ reduction in hospitalizations for acute coronary events (pooled RR: 0.88, $95 \%$ CI: 0.85- 0.90). Reductions were $14 \%$ in locations that implemented comprehensive legislations compared to an $8 \%$ reduction in locations that only had partial restrictions. In locations with reductions in smoking prevalence post-legislation above the mean $(2.1 \%$ reduction) there was a $14 \%$ reduction in events compared to $10 \%$ in locations below the mean. The RRs for acute coronary events associated with enacting smoke-free legislation were 0.87 vs. 0.89 in locations with smoking prevalence prelegislation above and below the mean (23.1\%), and 0.87 vs. 0.89 in studies from the Americas vs. other regions.

Conclusion The implementation of smoke-free legislations was related to reductions in acute coronary event hospitalizations in most populations evaluated. Benefits are greater in locations with comprehensive legislations and with greater reduction in smoking prevalence post-legislation. These cardiovascular benefits reinforce the urgent need to enact and enforce smoke-free legislations that protect all citizens around the world from exposure to tobacco smoke in public places.

Keywords Tobacco smoke pollution - Smoke-free policy · Cardiovascular diseases $\cdot$ Legislations 


\section{Introduction}

Epidemiological and experimental studies have shown that short-term and long-term exposure to secondhand smoke can have substantial adverse impacts on the cardiovascular system [1]. Governments worldwide, in compliance with Article 8 of the World Health Organization Framework Convention on Tobacco Control (FCTC), are implementing legislation banning smoking in indoor public places and worksites to protect citizens from exposure to secondhand smoke (SHS) [2]. The tobacco industry has also acknowledged the effectiveness of smoke-free legislations in reducing tobacco use [3-7]. Smokefree legislations range from partial bans where smoking is allowed in some public places (e.g., bars and/or restaurants) to comprehensive smoking bans whereby smoking is banned in all public places and workplaces. To date, only $16 \%$ of the world's population is protected from exposure to secondhand smoke by comprehensive, national smoke-free laws [8••].

Several systematic reviews have reported significant reductions in acute coronary events hospitalizations following the enactment of smoke-free legislations, with reductions ranging from 5 to $70 \%$ across studies (Supplementary Table 1) [9-11, 12•, 13-16]. Reductions in events following legislation were generally greater in studies with longer follow-up postlegislation $[11,13,14]$. The greater reductions in events observed in studies with longer follow-up may reflect larger reductions in secondhand smoke exposure after vs. before legislation. Secondhand smoke exposure before and after legislation implementation varies among studies for a variety of reasons including smoking prevalence pre-legislation, type of ban (comprehensive vs. partial), and the change in the smoking prevalence following legislation implementation. These factors are likely to influence effect size and explain heterogeneity across studies. Previous systematic reviews, however, have not examined the role of these factors as they relate to the changes in acute coronary events. Our objective was to systematically review the evidence on the impact of smoke-free legislation on subsequent hospitalizations for acute coronary events. We also aimed to investigate the potential impact of factors such as smoking ban coverage, prelegislation smoking prevalence, and changes in smoking prevalence following the legislation on the magnitude of the change in acute coronary events.

\section{Methods}

Search Strategy and Study Selection

We searched MEDLINE (PubMed) and EMBASE databases for studies assessing the association between smoke-free legislation and cardiovascular disease by using the following as free text, synonyms, explosion, and Medical Subject Headings
(MeSH): tobacco smoke pollution, secondhand smoke, environmental tobacco smoke, smoke-free legislation, and cardiovascular disease. The search was conducted without language restrictions on all articles from the beginning of indexing in each database through December 2013. In addition, we manually reviewed the reference lists from relevant research and review articles, including previous systematic reviews summarized in Table 1. Our exclusion criteria were: (1) study not conducted in humans; (2) publications containing no original data, including reviews, editorials, and commentaries; (3) no data comparing pre- and post-smoking legislation; (4) no acute coronary syndrome outcomes (e.g., hospitalizations or mortality); and (5) case reports. Articles that did not have available fulltext (e.g., abstracts from meetings) and non-peer reviewed literature were excluded. For studies that were not in English, the article was translated by a native speaker if the information in the abstract was insufficient to include/exclude the article. We also excluded two studies that used simulations to estimate the impact of smoke-free legislations $[17,18]$. When several papers had been published on the same population [19-30], we selected the publication with the longest follow-up period or the most recent publication (if follow-up periods were equivalent) [19, 26-29]. Several studies reported the impact of city smoking legislation [21, 23, 31-36] and were later followed by publications reporting state-wide (for US studies) or national legislation [22, $37,38]$. Due to the potential for overlap in study populations, we excluded studies that reported the impact of city legislations and reported data from state/country-wide studies.

\section{Data Abstraction}

Two investigators (M.R.J. and L.L.) independently abstracted study data from articles that met the inclusion criteria. Data included the study design, population, smoke-free legislation type (partial vs. comprehensive), follow-up time periods, outcome (acute coronary syndrome vs. acute myocardial infarction), measure of association (e.g., relative risk, rate ratio, percent reduction) and potential confounders accounted for in the statistical analysis. For studies with multiple levels of adjustment, we abstracted the measure of association obtained from the model adjusted for the most covariates. Discrepancies were resolved by consensus.

\section{Characteristics of Location and Study Population}

Characteristics of the city or country enacting legislation were extracted from data reported in the publication and included region (the Americas, Europe, and Other), type of ban (comprehensive vs. partial) and pre-legislation smoking prevalence. A comprehensive smoking ban includes banning smoking in public places including restaurants and bars. Partial restrictions exclude bars and/or restaurants. Pre-legislation smoking prevalence was defined based on data reported in the 


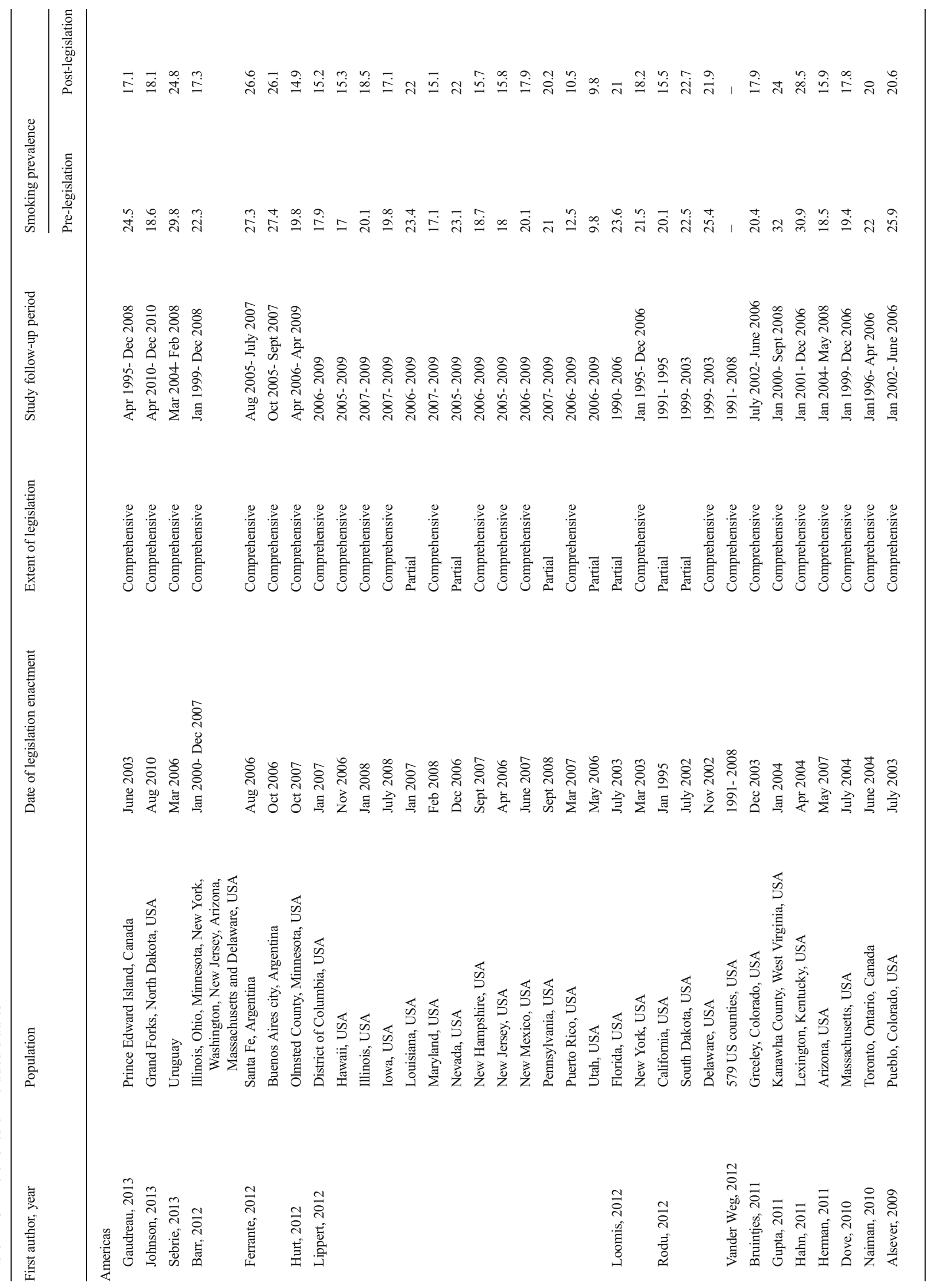




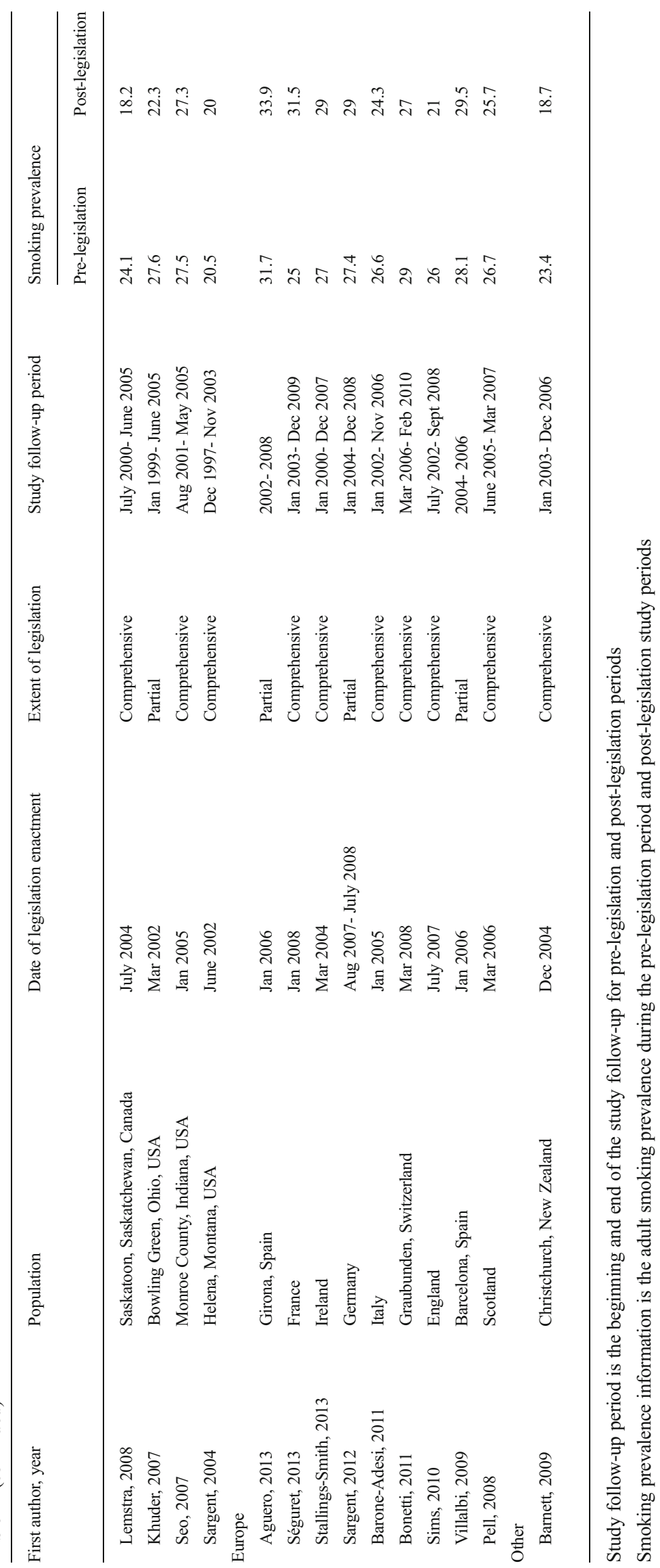


publication [19, 27, 39-43]. When pre-legislation smoking prevalence was not reported, it was estimated using data from the country for non-US studies [44-56] and the state/province or city for studies in the US or Canada [57-60]. One study [61] combined data from nine US states; for this study, the smoking prevalence was defined as the mean prevalence across the states. Vander Weg et al [62]. estimated the impact of 938 smoking legislations implemented in 731 cities, 175 counties, and 32 states in the US, however, this study did not provide information regarding the study locations to estimate pre- or post-smoking prevalence and therefore was excluded from the smoking prevalence analyses. Studies were defined as having a high or low pre-legislation prevalence of smoking and high or low reductions in prevalence of smoking following legislation using the mean pre-legislation prevalence $(23.1 \%)$ and mean prevalence reduction $(2.1 \%)$ as cutpoints.

\section{Statistical Analysis}

Relative risks (RR) for acute coronary events post- vs. prelegislation and their standard errors or $95 \%$ confidence intervals $(\mathrm{CI})$ were abstracted or derived using the data reported in each publication. The studies were then pooled using inversevariance weighted random-effects models. For those that reported stratified data only [38,63-65], an overall estimate was calculated by pooling the stratified estimates using inversevariance weighted random-effects models.

To evaluate the consistency of findings by location characteristics, pooled RRs were estimated separately for studies stratified by region, type of ban, pre-legislation smoking prevalence, and the change in prevalence post-legislation. Random-effects meta-regression was conducted to assess the association between the change in events after legislation with region (Americas vs. Other), pre-legislation smoking prevalence (above and below the mean), and change in smoking prevalence pre- vs. post-legislation (above and below the mean). Statistical heterogeneity was evaluated with the I [2] statistic to quantify the proportion of variability in effect estimates due to heterogeneity between studies versus sampling error within studies. The relative influence of each study on pooled estimates was estimated by omitting one study at a time. Finally, we assessed publication bias using funnel plots. All statistical analyses were performed using Stata version 13.1 (StataCorp, College Station, Texas).

\section{Results}

Study Selection

Of 1,672 studies identified, 31 studies [22, 26-29, 37-43, 61-77] met the inclusion criteria and were included in this review (Supplementary Figure 1). The article from McAlister et al [78]. included in the most recently published systematic review ${ }^{12}$ was excluded, as it did not meet our eligibility criteria (this study estimated the effects of tobacco control activities, especially smoking cessation programs, but did not include a smoking ban in public places). We also excluded meeting abstracts and articles from non-peer reviewed literature that were included in the systematic review from Tan et al [15]. Four US studies included estimates from multiple states [26-28, 62]. For the three studies [26-28] that provided estimates stratified by state, we considered the statespecific estimates as independent observations. The 31 included studies provided estimates from 47 locations.

\section{Study Characteristics}

Thirty-seven study locations were in the Americas (three in Canada, three in South America, and 31 in the US), nine in Europe, and one in New Zealand (Table 1). Legislations were implemented between 1991 and 2010, and study follow-up ranged from three months to 5.5 years postlegislation. Of the 47 total study locations, 35 were comprehensive smoking bans and 12 were partial smoking bans. The mean pre- and post-legislation smoking prevalences were 23.1 and $21.0 \%$, respectively, for locations included in this review.

\section{Smoking Legislations and Acute Coronary Events}

Changes in hospitalizations for acute coronary events ranged from a $52 \%$ reduction in Monroe County, Indiana [77] to a $9 \%$ increase in South Dakota [26]. Overall, the enactment of smoking legislations was associated with a $12 \%$ reduction in acute coronary events (pooled RR: 0.88, $95 \%$ CI: 0.85-0.90). Comprehensive smoke-free legislations were associated with a $14 \%$ reduction in hospitalizations (pooled RR: 0.86, 95 \% CI: 0.83-0.89) (Fig. 1, Table 2) compared to an $8 \%$ reduction for partial smoking restrictions (Pooled RR: 0.92, $95 \%$ CI: 0.85, 0.98) (Fig. 2, Table 2). Reductions were largely similar in studies conducted in the Americas (Pooled RR: 0.87, $95 \%$ CI: 0.83, 0.91) compared to elsewhere (Pooled RR: $0.89,95 \%$ CI: $0.84,0.94)$.

Median (Interquartile range [IQR]) pre- and postlegislation smoking prevalence were 23.3 (19.8- 27.0) $\%$ and 20.1 (17.1- 25.7) \%, respectively. The reduction in acute coronary events following smoking legislation was greater among populations with higher smoking prevalences pre-legislation compared to populations with lower smoking prevalences (Pooled RR [95\% $\mathrm{CI}]: 0.87$ [0.83, 0.91] for pre-legislation smoking prevalence above the mean vs. $0.89[0.85,0.93]$ for pre- 


\begin{tabular}{ll} 
Study & Location \\
Americas & \\
Gaudreau 2013 & Prince Edward Island, Canada \\
Johnson 2013 & Grand Forks, ND, USA \\
Sebrie 2013 & Uruguay \\
Barr 2012 & IL, OH,MN,NY,WA, NJ,AZ,MA, DE, USA \\
Ferrante 2012 & Santa Fe, Argentina \\
Hurt 2012 & Olmsted County, MN, USA \\
Lippert 2012 & District of Columbia, USA \\
Lippert 2012 & Hawaii, USA \\
Lippert 2012 & Illinois, USA \\
Lippert 2012 & lowa, USA \\
Lippert 2012 & Maryland, USA \\
Lippert 2012 & New Hampshire, USA \\
Lippert 2012 & New Jersey, USA \\
Lippert 2012 & New Mexico, USA \\
Lippert 2012 & Puerto Rico, USA \\
Loomis 2012 & New York, USA \\
Rodu 2012 & Delaware, USA \\
Vander Weg 2012 & 32 US states, USA \\
Bruintjes 2011 & Greeley, CO, USA \\
Gupta 2011 & Kanawha County, WW, USA \\
Hahn 2011 & Lexington, KY, USA \\
Herman 2011 & Arizona, USA \\
Dove 2010 & Massachusetts, USA \\
Naiman 2010 & Toronto, ON, Canada \\
Alsever 2009 & Pueblo, CO, USA \\
Lemstra 2008 & Saskatoon, SK, Canada \\
Seo 2007 & Monroe County, IN, USA \\
Sargent 2004 & Helena, MN, USA \\
Europe & \\
Seguret 2013 & France \\
Stallings-Smith 2013 & Ireland \\
Barone-Adesi 2011 & Italy \\
Bonetti 2011 & Graubunden, Switzerland \\
Sims 2010 & England \\
Pell 2008 & Scotland \\
Other & \\
Barnett 2009 & Christchurch, New Zealand \\
Overall Pooled RR & \\
& \\
\hline
\end{tabular}

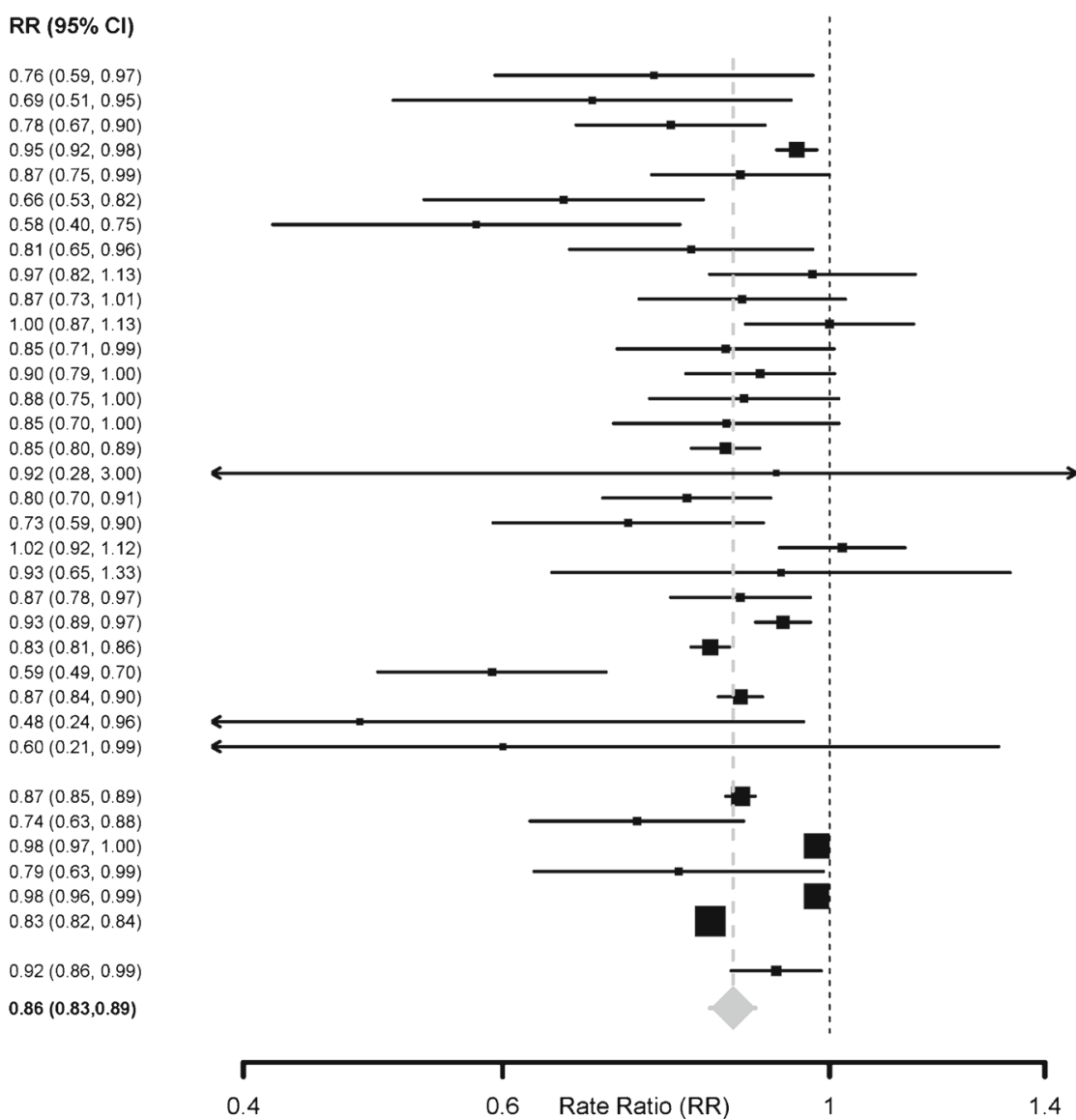

Fig. 1 Forest plot of random-effects meta-analysis of studies examining the effect of comprehensive smoke-free legislation on acute coronary events

legislation smoking prevalence below the mean) (Table 2). Following enactment of smoke-free legislation, the prevalence of smoking decreased on average by $2.1 \%$, with seven locations observing no change or an increase in smoking prevalence in the postlegislation period $[26,27,37,65,73,76,79]$. The reduction in events following legislation was also larger in locations with reductions in smoking prevalence above versus below the mean (Pooled RR: 0.86 [95\%
CI: $0.83,0.89]$ vs 0.90 [95 \% CI: $0.88,0.93])$ (Table 2).

\section{Discussion}

Following the enactment of smoke-free legislations, there was a $12 \%$ reduction in hospitalizations for acute coronary events
Table 2 Pooled estimates of the effect of smoking legislation on acute coronary events by type of legislation and smoking prevalence data

Pooled estimates from randomeffects meta-analyses

\begin{tabular}{lll}
\hline & No of estimates & Pooled RR (95 \% CI) \\
\hline $\begin{array}{l}\text { Overall } \\
\text { Type of legislation }\end{array}$ & 47 & $0.88(0.85,0.90)$ \\
$\quad$ Comprehensive (smoke-free) & 35 & $0.86(0.83,0.89)$ \\
$\quad$ Partial smoking restriction & 12 & $0.92(0.85,0.98)$ \\
Pre-legislation smoking prevalence & & $0.89(0.85,0.93)$ \\
Below the mean $(\leq 23.1 \%)$ & 22 & $0.87(0.83,0.91)$ \\
Above the mean $(>23.1 \%)$ & 24 & $0.90(0.88,0.93)$ \\
Reduction in smoking prevalence post vs. pre-legislation & & $0.86(0.83,0.89)$ \\
Below the mean $(\leq 2.1 \%$ reduction $)$ & 23 & 23
\end{tabular}




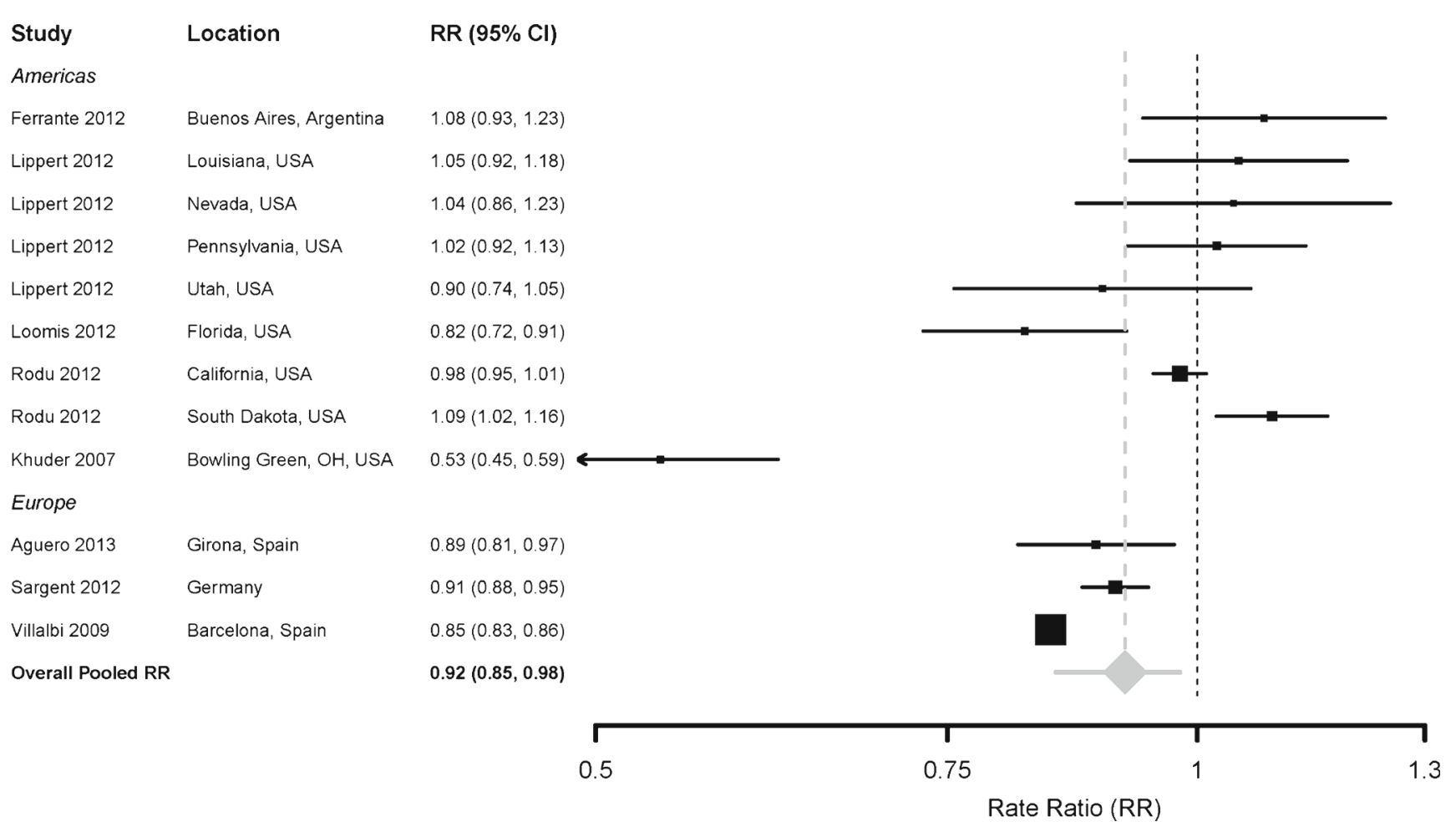

Fig. 2 Forest plot of random-effects meta-analysis of studies examining the effect of partial smoke-free legislation on acute coronary events

with greater reductions with comprehensive, as opposed to partial, smoke-free legislation. Comprehensive smoke-free laws have been shown to be more effective than partial laws in reducing exposure to secondhand tobacco smoke [80, 81]. Indeed, while a reduction in fine particulate matter $\left(\mathrm{PM}_{2.5}\right)$ concentrations had been observed in France, Greece, Ireland, Italy, Portugal, Scotland, and Turkey following enactment of smoke-free legislations, the countries that enacted comprehensive smoke-free legislation (France, Ireland, Italy, Scotland, and Turkey) experienced greater reductions in $\mathrm{PM}_{2.5}$ concentrations [82]. In studies in Malaysia and Chile, which have partial smoking legislations, exposure to secondhand smoke, measured by air nicotine and $\mathrm{PM}_{2.5}$ concentrations, remained high in hospitality venues following enactment of legislation [83, 84]. In Spain, which also enacted partial smoking restrictions, there was no change in concentrations of salivary cotinine among nonsmoking hospitality workers [85] and an increase in concentrations of airborne nicotine in hospitality venues [86] following legislation enactment. These findings demonstrate that partial smoking ban legislations do not provide protection from secondhand smoke to employees working in those venues. In contrast, among nonsmoking adults in Scotland, which enacted comprehensive smoking legislation, there was a $39 \%$ decrease in salivary cotinine concentrations following enactment [87].

With increasing time, larger reductions in cardiovascular hospitalizations $[11,13,14]$ and increasing support for smoking bans [88-90] have been found. Consistent with previous systematic reviews $[11,13,14]$, we found greater reductions in events following legislation in locations with follow-up above versus below the mean (25.8 months) (Pooled RR: 0.83 [95 \% CI: 0.78, 0.88] vs 0.91 [95 \% CI: $0.87,0.94])$. The larger reductions in hospitalizations over time may reflect greater reductions in secondhand smoke exposure in the population as well as decreases in the magnitude of active smoking (due to potential decreases in cigarette consumption and increases in smoking cessation) [30, 64]. Additionally, comprehensive smoke-free legislations have been associated with greater quit attempts and quit successes following legislation enactment compared to the enactment partial smoke-free legislations [91, 92]. In our study we observed greater reductions in coronary events in populations that enacted comprehensive smoke-free legislations and in populations that had greater reductions in smoking prevalence post-legislation.

Two recent papers published in January 2014 and February 2014 found no association between the enactment of the legislation and a reduction in cardiovascular events [93, 94]. The studies were conducted in Colorado and Panama. In Panama, the smoking prevalence prior to the legislation was very low (9\%) [94]. In the study conducted in Colorado [93], the statewide comprehensive legislation had been preceded by several city-wide smoking ordinances, including two cities included in this review [19, 67], which found significant decreases in acute myocardial infarction hospitalization after implementation of these local smoking ordinances. Following the enactment of these legislations, the prevalence of smoking 
was reduced by $2.4 \%$ and $2.6 \%$ in Colorado and Panama, respectively $[57,94]$. Adding those studies to the overall pooled estimates resulted in similar findings: RR: 0.88 (95 \% CI: 0.86, 0.91).

\section{Possible Mechanisms}

Mechanisms by which secondhand smoke may increase the risk for an acute coronary event include platelet activation, induction of endothelial dysfunction, increase in arterial stiffness, enhanced oxidative stress, reduced antioxidant defense, induction of inflammation, decreased parasympathetic output, and an increase in insulin resistance [1, 95-97]. These consequences have been observed at low exposure doses and within minutes or hours following exposure. This might explain why the beneficial effects of reducing secondhand smoke exposure seem to occur rapidly with declines in hospitalizations within a few months following legislation. Indeed, reductions were seen in studies with postlegislation periods as soon as a few months following the enactment of the legislation showing that the enactment of smoke-free legislation can result in immediate reductions in hospital admissions and these reductions increase over time following legislation enactment.

\section{Strengths and Limitations}

This study has several strengths. Our results are consistent with those of prior systematic reviews and metaanalyses [9-11, 12•, 13-15], which also reported a significant reduction in hospitalizations for acute coronary events following the implementation of smoke-free legislations, and include additional recent studies and several larger population studies (Supplementary Table 1). Moreover, we evaluated differences in the association between legislation and acute coronary events by several characteristics, including type of legislation, prelegislation smoking prevalence, and changes in smoking prevalence. Our findings add to the current literature regarding the benefits of smoke-free legislation.

Some limitations should be noted. In this review, we examined differences in hospitalizations with changes in prevalence of smoking, however, as many of the studies do not have information on changes in secondhand smoke exposure pre- vs. post legislation, it is difficult to determine what portion of the observed decreases in hospital admissions could be attributed to reduced exposure to secondhand tobacco smoke in nonsmokers as opposed to reduced consumption or quitting among smokers. Also, there were small sample sizes in some studies, and most of the studies were ecological in design. The studies also differed by population demographics included in the study, for example, the age limits for inclusion, which may impact differences in the effects of the smoke-free legislations observed. Lastly, we were unable to evaluate the influence of enforcement or compliance with the legislation, remaining secondhand smoke exposure in areas not covered by the legislation (e.g., private vehicles and homes), or baseline rates of acute coronary events. These factors could also influence the magnitudes of the reductions following the implementation of smoke-free legislation. Additionally, countries and cities can implement other type of FCTC articles that can also impact smoking prevalence and coronary events, for example, tobacco tax increases and reductions in tobacco advertising and promotion [94]. We were unable to evaluate the influence of other such measures that may have occurred concurrently with the smoking bans in public places. This analysis examines changes in cardiovascular events following the implementation of smoke-free legislations compared to the time period prior to the legislations as reported in the studies. For comprehensive legislations, especially those conducted in the US, the pre-legislation period may include partial smoke-free legislations. Therefore, we were limited to examining the gradual changes in cardiovascular events that occur as smokefree legislations are implemented (i.e., when there are no restrictions followed by the implementation of a partial smoke-free legislation and then comprehensive legislation).

\section{Conclusion}

The implementation of smoke-free legislations was related to a reduction in hospitalizations for acute coronary events. These cardiovascular benefits were greater in studies conducted in populations with comprehensive smoking bans, and in populations with greater reductions in smoking prevalence. These data support the urgent need to enact and enforce smoke-free legislations that protect all people from exposure to secondhand tobacco smoke.

Acknowledgments This work was supported by the US National Cancer Institute (R03CA153959) and a Clinical Investigator Award from the Flight Attendant Medical Research Institute (FAMRI). Miranda R Jones was also supported by the National Cancer Institute's Cancer Epidemiology, Prevention and Control Training Grant (T32 CA009314).

\section{Compliance with Ethics Guidelines}

Conflict of Interest Miranda R. Jones, Joaquin Barnoya, Saverio Stranges, Lia Losonczy, and Ana Navas-Acien declare that they have no conflicts of interest. 
Human and Animal Rights and Informed Consent This article does not contain any studies with human or animal subjects performed by any of the authors.

\section{References}

Papers of particular interest, published recently, are highlighted as:

- Of importance

- Of major importance

1. Barnoya J, Glantz SA. Cardiovascular effects of secondhand smoke: nearly as large as smoking. Circulation. 2005;111(20): 2684-98.

2. World Health Organization (WHO). WHO framework convention on tobacco control. Geneva, Switzerland: World Health Organization (WHO); 2005.

3. An action plan for ETS in Europe and adjacent areas, 19891992. 1988

4. Barnoya J, Glantz SA. The tobacco industry and secondhand smoke: lessons from Central and South America. Ethn Dis. 2003;13(2 Suppl 2):S88-90.

5. Chapman S, Borland R, Hill D, Owen N, Woodward S. Why the tobacco industry fears the passive smoking issue. Int J Health Serv. 1990;20(3):417-27.

6. Glantz SA. Achieving a smokefree society. Circulation. 1987;76(4):746-52.

7. Heironimus J. Impact of workplace restrictions on consumption and incidence. 1992

8.• World Health Organization (WHO). WHO Report on the Global Tobacco Epidemic. Geneva, Switzerland: World Health Organization (WHO) Member States; 2013. This report details tobacco use and the status of tobacco control policies including information on smoke-free legislations and legislations banning tobacco advertising and promotion in World Health Organization (WHO) Member States.

9. Bolte G, Kuhn J, Twardella D, Fromme H. [Smoking bans in public places: current epidemiological evidence of cardiovascular health impacts at the population level]. Gesundheitswesen. 2009;71(3): 140-51.

10. Jankowski P, Brzozowska-Kiszka M, Debicka-Dabrowska D, Kawecka-Jaszcz K. [The influence of ban on smoking on admissions due to acute coronary syndromes - a systematic review]. Kardiol Pol. 2008;66(10):1107-12.

11. Lightwood JM, Glantz SA. Declines in acute myocardial infarction after smoke-free laws and individual risk attributable to secondhand smoke. Circulation. 2009;120(14):1373-9.

12. Lin $\mathrm{H}$, Wang $\mathrm{H}$, Wu W, Lang $\mathrm{L}$, Wang Q, Tian L. The effects of smoke-free legislation on acute myocardial infarction: a systematic review and meta-analysis. BMC Public Health. 2013;13:529. This study is the most recent systematic review that examined the reduction in risk of acute myocardial infarction occurrence following the smoke-free legislations as well as the relationship with the corresponding changes in smoking prevalence.

13. Mackay DF, Irfan MO, Haw S, Pell JP. Meta-analysis of the effect of comprehensive smoke-free legislation on acute coronary events. Heart. 2010;96(19):1525-30.
14. Meyers DG, Neuberger JS, He J. Cardiovascular effect of bans on smoking in public places: a systematic review and meta-analysis. J Am Coll Cardiol. 2009;54(14):1249-55.

15. Tan CE, Glantz SA. Association between smoke-free legislation and hospitalizations for cardiac, cerebrovascular, and respiratory diseases: a meta-analysis. Circulation. 2012;126(18):2177-83.

16. Jones MR, Stranges S, Losonczy L, Barnoya J, Apelberg B, Navas-Acien A. Acute coronary events following enactment of smoke-free legislation: A systematic review and metaanalysis. San Francisco, CA: American Heart Association, Cardiovascular Disease Epidemiology and Prevention Scientific Sessions; 2010.

17. Basu S, Glantz S, Bitton A, Millett C. The effect of tobacco control measures during a period of rising cardiovascular disease risk in India: a mathematical model of myocardial infarction and stroke. PLoS Med. 2013;10(7):e1001480.

18. Ong MK, Glantz SA. Cardiovascular health and economic effects of smoke-free workplaces. Am J Med. 2004;117(1):32-8.

19. Alsever RN, Thomas WM, Nevin-Woods C, Beauvais R, Dennison $\mathrm{S}$, Bueno R, et al. Reduced hospitalizations for acute myocardial infarction after implementation of a smoke-free ordinance-City of Pueblo, Colorado, 2002-2006. MMWR Morb Mortal Wkly Rep. 2009;57(51):1373-7.

20. Bartecchi C, Alsever RN, Nevin-Woods C, Thomas WM, Estacio $\mathrm{RO}$, Bartelson $\mathrm{BB}$, et al. Reduction in the incidence of acute myocardial infarction associated with a citywide smoking ordinance. Circulation. 2006;114(14):1490-6.

21. Barone AF, Vizzini L, Merletti F, Richiardi L. Italian smoking regulation decreased hospital admissions for acute coronary events:effect modification by age and day of the week. Eur Heart J. 2009;30 SUPPL. 1:148.

22. Barone-Adesi F, Gasparrini A, Vizzini L, Merletti F, Richiardi L. Effects of Italian smoking regulation on rates of hospital admission for acute coronary events: a country-wide study. PLoS ONE. 2011;6(3):e17419.

23. Barone-Adesi F, Vizzini L, Merletti F, Richiardi L. Short-term effects of Italian smoking regulation on rates of hospital admission for acute myocardial infarction. Eur Heart J. 2006;27(20):2468-72.

24. Juster HR, Loomis BR, Hinman TM, Farrelly MC, Hyland A, Bauer UE, et al. Declines in hospital admissions for acute myocardial infarction in New York state after implementation of a comprehensive smoking ban. Am J Public Health. 2007;97(11):2035-9.

25. Moraros J, Bird Y, Chen S, Buckingham R, Meltzer RS, Prapasiri S, et al. The impact of the 2002 Delaware smoking ordinance on heart attack and asthma. Int J Environ Res Public Health. 2010;7(12): 4169-78.

26. Rodu B, Peiper N, Cole P. Acute myocardial infarction mortality before and after state-wide smoking bans. J Community Health. 2012;37(2):468-72.

27. Lippert WC, Gustat J. Clean Indoor Air Acts reduce the burden of adverse cardiovascular outcomes. Public Health. 2012;126(4):279-85.

28. Loomis BR, Juster HR. Association of indoor smoke-free air laws with hospital admissions for acute myocardial infarction and stroke in three states. J Environ Public Health. 2012;2012:589018.

29. Bonetti PO, Trachsel LD, Kuhn MU, Schulzki T, Erne P, Radovanovic D, et al. Incidence of acute myocardial infarction after implementation of a public smoking ban in Graubunden. Switzerland: two year follow-up. Swiss Med Wkly. 2011;141: w13206.

30. Trachsel LD, Kuhn MU, Reinhart WH, Schulzki T, Bonetti PO. Reduced incidence of acute myocardial infarction in the first year after implementation of a public smoking ban in Graubuenden, Switzerland. Swiss Med Wkly. 2010;140(910):133-8. 
31. Cesaroni G, Forastiere F, Agabiti N, Valente P, Zuccaro P, Perucci CA. Effect of the Italian smoking ban on population rates of acute coronary events. Circulation. 2008;117(9):1183-8.

32. Cronin EM, Kearney PM, Kearney PP, Sullivan P, Perry IJ. Impact of a national smoking ban on hospital admission for acute coronary syndromes: a longitudinal study. Clin Cardiol. 2012;35(4):205-9.

33. Gasparrini A, Gorini G, Barchielli A. On the relationship between smoking bans and incidence of acute myocardial infarction. Eur J Epidemiol. 2009;24(10):597-602.

34. Kent BD, Sulaiman I, Nicholson TT, Lane SJ, Moloney ED. Acute pulmonary admissions following implementation of a national workplace smoking ban. Chest. 2012;142(3):673-9.

35. Liu A, Castillo MG, Capewell S, Lucy J, O'Flaherty M. Reduction in myocardial infarction admissions in Liverpool after the smoking ban: Potential socioeconomic implications for policymaking. BMJ Open. 2013;3(11 Article Number).

36. Vasselli S, Papini P, Gaelone D, Spizzichino L, De CE, Gnavi R, et al. Reduction incidence of myocardial infarction associated with a national legislative ban on smoking. Minerva Cardioangiol. 2008;56(2):197-203.

37. Stallings-Smith S, Zeka A, Goodman P, Kabir Z, Clancy L. Reductions in cardiovascular, cerebrovascular, and respiratory mortality following the national irish smoking ban: interrupted timeseries analysis. PLoS ONE. 2013;8(4):e62063.

38. Sims M, Maxwell R, Bauld L, Gilmore A. Short term impact of smoke-free legislation in England: retrospective analysis of hospital admissions for myocardial infarction. BMJ. 2010;340:c2161.

39. Ferrante D, Linetzky B, Virgolini M, Schoj V, Apelberg B. Reduction in hospital admissions for acute coronary syndrome after the successful implementation of $100 \%$ smoke-free legislation in Argentina: a comparison with partial smoking restrictions. Tob Control. 2012;21(4):402-6.

40. Gaudreau K, Sanford CJ, Cheverie C, McClure C. The Effect of a Smoking Ban on Hospitalization Rates for Cardiovascular and Respiratory Conditions in Prince Edward Island, Canada. PLoS ONE. 2013;8(3 Article Number).

41. Gupta R, Luo J, Anderson RH, Ray A. Clean indoor air regulation and incidence of hospital admissions for acute coronary syndrome in Kanawha County, West Virginia. Prev Chronic Dis 2011;8(4): A77.

42. Hurt RD, Weston SA, Ebbert JO, McNallan SM, Croghan IT, Schroeder DR, et al. Myocardial infarction and sudden cardiac death in Olmsted County, Minnesota, before and after smoke-free workplace laws. Arch Intern Med. 2012;172(21):1635-41.

43. Lemstra M, Neudorf C, Opondo J. Implications of a public smoking ban. Can J Public Health. 2008;99(1):62-5.

44. World Health Organization (WHO). The European Tobacco Control Report, 2007. Geneva, Switzerland: World Health Organization (WHO); 2007.

45. Regidor E, de Mateo S, Ronda E, Sanchez-Paya J, Gutierrez-Fisac JL, de la Fuente L, et al. Heterogeneous trend in smoking prevalence by sex and age group following the implementation of a national smoke-free law. J Epidemiol Community Health. 2011;65(8):702-8.

46. Ministry of Health. A Portrait of Health. Key Results of the 2002/03 New Zealand Health Survey. Wellington, New Zealand; 2004.

47. Ministry of Health. A Portrait of Health. Key Results of the 2006/07 New Zealand Health Survey. Wellington, New Zealand; 2008.

48. Gallus S, Colombo P, Scarpino V, Zuccaro P, Apolone G, La Vecchia C. Smoking in Italy, 2002. Tumori. 2002;88(6):453-6.

49. Gallus S, Zuccaro P, Colombo P, Apolone G, Pacifici R, Garattini S, et al. Smoking in Italy 2005-2006: effects of a comprehensive National Tobacco Regulation. Prev Med. 2007;45(2-3):198-201.

50. Keller R, Radtke T, Krebs H, Hornung R. Der Tabakkonsum der Schweizer Wohnbevölkerung in den Jahren 2001 bis 2010. Tabakmonitoring- Schweizerische Umfrage zum Tabakkonsum.
Zürich: Psychologisches Institut der Universität Zürich, Sozialund Gesundheitspsychologie; 2011.

51. Krzyzanowski N. Annual Report: Results from 2012 Scottish Household Survey. Scotland's People Edinburgh; 2013.

52. Blank TW. World Development Indicators: Health risk factors and future challenges. DC: Washington; 2014.

53. Muller F, Wehbe L. Smoking and smoking cessation in Latin America: a review of the current situation and available treatments. Int J Chron Obstruct Pulmon Dis. 2008;3(2):285-93.

54. Centers for Disease Control and Prevention (CDC). Global Adult Tobacco Survey Fact Sheet: Uruguay. Atlanta; 2009.

55. Robinson S, Bugler C. Smoking and drinking among adults 2008. General Lifestyle Survey 2008. Newport; 2010.

56. Eurostat European Commission. Health Status of the Population of Ireland, 2008. Luxembourg: National Health Interview Surveys; 2008.

57. Centers for Disease Control and Prevention (CDC). Behavioral Risk Factor Surveillance System, 1984-2009 and Selected Morbidity and Mortality Weekly Reports. 2011.

58. Centers for Disease Control and Prevention (CDC). State Highlights: North Dakota. Atlanta, GA; 2011.

59. Partners P. Report on the Health Status of the Residents of Ontario. 2000

60. Ontario Tobacco Research Unit. Smoke-Free Ontario Strategy Evaluation Report. Toronto: Ontario Tobacco Research Unit; 2011.

61. Barr CD, Diez DM, Wang Y, Dominici F, Samet JM. Comprehensive smoking bans and acute myocardial infarction among Medicare enrollees in 387 US counties: 1999-2008. Am J Epidemiol. 2012;176(7):642-8.

62. Vander Weg MW, Rosenthal GE, Vaughan SM. Smoking bans linked to lower hospitalizations for heart attacks and lung disease among medicare beneficiaries. Health Aff(Millwood). 2012;31(12):2699-707.

63. Hahn EJ, Rayens MK, Burkhart PV, Moser DK. Smoke-free laws, gender, and reduction in hospitalizations for acute myocardial infarction. Public Health Rep. 2011;126(6):826-33.

64. Pell JP, Haw S, Cobbe S, Newby DE, Pell AC, Fischbacher C, et al. Smoke-free legislation and hospitalizations for acute coronary syndrome. N Engl J Med. 2008;359(5):482-91.

65. Villalbi JR, Castillo A, Cleries M, Salto E, Sanchez E, Martinez R, et al. Acute myocardial infarction hospitalization statistics: apparent decline accompanying an increase in smoke-free areas. Rev Esp Cardiol. 2009;62(7):812-5.

66. Barnett R, Pearce J, Moon G, Elliott J, Barnett P. Assessing the effects of the introduction of the New Zealand Smokefree Environment Act 2003 on acute myocardial infarction hospital admissions in Christchurch, New Zealand. Aust N Z J Public Health. 2009;33(6):515-20.

67. Bruintjes G, Bartelson BB, Hurst P, Levinson AH, Hokanson JE, Krantz MJ. Reduction in acute myocardial infarction hospitalization after implementation of a smoking ordinance. Am J Med. 2011;124(7):647-54.

68. Dove MS, Dockery DW, Mittleman MA, Schwartz J, Sullivan EM, Keithly L, et al. The impact of Massachusetts' smoke-free workplace laws on acute myocardial infarction deaths. Am J Public Health. 2010;100(11):2206-12.

69. Herman PM, Walsh ME. Hospital admissions for acute myocardial infarction, angina, stroke, and asthma after implementation of Arizona's comprehensive statewide smoking ban. Am J Public Health. 2011;101(3):491-6.

70. Johnson EL, Beal JR. Impact of a comprehensive smoke-free law following a partial smoke-free law on incidence of heart attacks at a rural community hospital. Nicotine Tob Res. 2013;15(3):745-7.

71. Khuder SA, Milz S, Jordan T, Price J, Silvestri K, Butler P. The impact of a smoking ban on hospital admissions for coronary heart disease. Prev Med. 2007;45(1):3-8. 
72. Naiman A, Glazier RH, Moineddin R. Association of anti-smoking legislation with rates of hospital admission for cardiovascular and respiratory conditions. CMAJ. 2010;182(8):761-7.

73. Sargent JD, Demidenko E, Malenka DJ, Li Z, Gohlke H, Hanewinkel R. Smoking restrictions and hospitalization for acute coronary events in Germany. Clin Res Cardiol. 2012;101(3):227-35.

74. Sargent RP, Shepard RM, Glantz SA. Reduced incidence of admissions for myocardial infarction associated with public smoking ban: before and after study. BMJ. 2004;328(7446):977-80.

75. Sebrie EM, Sandoya E, Hyland A, Bianco E, Glantz SA, Cummings KM. Hospital admissions for acute myocardial infarction before and after implementation of a comprehensive smoke-free policy in Uruguay. Tob Control. 2013;22(e1):e16-20.

76. Seguret F, Ferreira C, Cambou JP, Carriere I, Thomas D. Changes in hospitalization rates for acute coronary syndrome after a two-phase comprehensive smoking ban. Eur J Prev Cardiol. 2013.

77. Seo DC, Torabi MR. Reduced admissions for acute myocardial infarction associated with a public smoking ban: matched controlled study. J Drug Educ. 2007;37(3):217-26.

78. McAlister AL, Huang P, Ramirez AG, Harrist RB, Fonseca VP. Reductions in cigarette smoking and acute myocardial infarction mortality in Jefferson County. Texas Am J Publ Health. 2010;100(12):2391-2.

79. Aguero F, Degano IR, Subirana I, Grau M, Zamora A, Sala J, et al. Impact of a partial smoke-free legislation on myocardial infarction incidence, mortality and case-fatality in a population-based registry: the REGICOR Study. PLoS ONE. 2013;8(1):e53722.

80. Nagelhout GE, Mons U, Allwright S, Guignard R, Beck F, Fong GT, et al. Prevalence and predictors of smoking in "smoke-free" bars. Findings from the International Tobacco Control (ITC) Europe Surveys. Soc Sci Med. 2011;72(10):1643-51.

81. Naiman AB, Glazier RH, Moineddin R. Is there an impact of public smoking bans on self-reported smoking status and exposure to secondhand smoke? BMC Public Health. 2011;11:146.

82. Ward M, Currie LM, Kabir Z, Clancy L. The efficacy of different models of smoke-free laws in reducing exposure to second-hand smoke: a multi-country comparison. Health Policy. 2013;110(2-3): 207-13.

83. Abidin EZ, Hashim Z, Semple S. Second-hand smoke in public spaces: how effective has partial smoke-free legislation been in Malaysia? Asian Pac J Cancer Prev. 2013;14(11):6845-50.

84. Erazo M, Iglesias V, Droppelmann A, Acuna M, Peruga A, Breysse $\mathrm{PN}$, et al. Secondhand tobacco smoke in bars and restaurants in Santiago, Chile: evaluation of partial smoking ban legislation in public places. Tob Control. 2010;19(6):469-74.
85. Fernandez E, Fu M, Pascual JA, Lopez MJ, Perez-Rios M, Schiaffino A, et al. Impact of the Spanish smoking law on exposure to second-hand smoke and respiratory health in hospitality workers: a cohort study. PLoS ONE. 2009;4(1):e4244.

86. Lopez MJ, Nebot M, Schiaffino A, Perez-Rios M, Fu M, Ariza C, et al. Two-year impact of the Spanish smoking law on exposure to secondhand smoke: evidence of the failure of the 'Spanish model'. Tob Control. 2012;21(4):407-11.

87. Haw SJ, Gruer L. Changes in exposure of adult non-smokers to secondhand smoke after implementation of smoke-free legislation in Scotland: national cross sectional survey. BMJ. 2007;335(7619):549.

88. Brooks DR, Mucci LA. Support for smoke-free restaurants among Massachusetts adults, 1992-1999. Am J Public Health. 2001;91(2): 300-3.

89. Hyland A, Higbee C, Borland R, Travers M, Hastings G, Fong GT, et al. Attitudes and beliefs about secondhand smoke and smoke-free policies in four countries: findings from the International Tobacco Control Four Country Survey. Nicotine Tob Res. 2009;11(6):642-9.

90. Osypuk TL, Acevedo-Garcia D. Support for smoke-free policies: a nationwide analysis of immigrants, US-born, and other demographic groups, 1995-2002. Am J Public Health. 2010;100(1):171-81.

91. Fong GT, Hyland A, Borland R, Hammond D, Hastings G, McNeill $\mathrm{A}$, et al. Reductions in tobacco smoke pollution and increases in support for smoke-free public places following the implementation of comprehensive smoke-free workplace legislation in the Republic of Ireland: findings from the ITC Ireland/UK Survey. Tob Control. 2006;15 Suppl 3:iii51-8.

92. Nagelhout GE, de Vries H, Boudreau C, Allwright S, McNeill A, van den Putte B, et al. Comparative impact of smoke-free legislation on smoking cessation in three European countries. Eur J Public Health. 2012;22 Suppl 1:4-9.

93. Basel P, Bartelson BB, Le Lait MC, Krantz MJ. The effect of a statewide smoking ordinance on acute myocardial infarction rates. Am J Med. 2014;127(1):94-e1-6.

94. Jan C, Lee M, Roa R, Herrera V, Politis M, Motta J. The association of tobacco control policies and the risk of acute myocardial infarction using hospital admissions data. PLoS ONE. 2014;9(2):e88784.

95. Barnoya J, Glantz SA. Cardiovascular effects of second-hand smoke help explain the benefits of smoke-free legislation on heart disease burden. J Cardiovasc Nurs. 2006;21(6):457-62.

96. Otsuka R, Watanabe H, Hirata K, Tokai K, Muro T, Yoshiyama M, et al. Acute effects of passive smoking on the coronary circulation in healthy young adults. J Am Med Assoc. 2001;286(4):436-41.

97. Pechacek TF, Babb S. How acute and reversible are the cardiovascular risks of secondhand smoke? BMJ. 2004;328(7446):980-3. 